\title{
Enhanced gastric retention of solid resin beads as a marker for emetic potential of agents in rats
}

\author{
Kentaro Ando ${ }^{1,2}$, Kan Takagi ${ }^{3}$ and Hirokazu Tsubone ${ }^{1}$ \\ 'Department of Comparative Pathophysiology, Graduate School of Agricultural and Life Sciences, \\ The University of Tokyo, 1-1-1 Yayoi, Bunkyo-ku, Tokyo, 113-8657, Japan \\ ${ }^{2}$ Drug Development Service Segment, Mitsubishi Chemical Medience Corporation, 4-2-8 Shibaura, \\ Minato-ku, Tokyo, 108-8559, Japan \\ ${ }^{3}$ Safety Research Laboratories, Research Division, Mitsubishi Tanabe Pharma Corporation, \\ 1-1-1 Kazusa-Kamatari, Kisarazu, Chiba 292-0818, Japan
}

(Received December 22, 2011; Accepted March 1, 2012)

\begin{abstract}
Whereas nausea and emesis are burdensome side effects that lead to poor treatment compliance especially in chemotherapy, it is difficult to predict the emetic potential of agents in rats and mice because rodents do not vomit. We examined the effect of emetics on gastric retention and role of serotonin (5-hydroxytryptamine, 5-HT) ${ }_{3}$ receptor in chemotherapeutic-induced enhancement of gastric retention in rats. The gastric retention of solid material was determined using resin beads, which were suitable to beads made with metals or glasses in size, hardness and weight. Each rat was orally given distilled water $(0.5 \mathrm{ml} / \mathrm{rat})$ containing 40 resin beads via a plastic feeding tube. The stomach was removed at $1 \mathrm{hr}$ postdose and cut along the greater curvature under carbon dioxide anesthesia. Beads were given immediately after administration of the drugs except with cisplatin, when there was a $1 \mathrm{hr}$ delay. Cancer chemotherapeutics including cisplatin( $0.1-3 \mathrm{mg} / \mathrm{kg}$ i.v. $)$ and doxorubicin $(0.3-10 \mathrm{mg} / \mathrm{kg}$ i.v. $)$ and a nauseant, copper sulfate( $1-30 \mathrm{mg} / \mathrm{kg}$ p.o.) enhanced gastric retention of beads. Ondansetron, a $5-\mathrm{HT}_{3}$ receptor antagonist, dose-dependently antagonized the enhanced gastric retention by cisplatin and doxorubicin. The copper sulfate-induced enhancement was also reversed by ondansetron. Our results suggest that $5-\mathrm{HT}_{3}$ receptors mediate the cancer chemotherapeutic-enhanced gastric retention of solid material in rats. This implicates that the gastric retention of solid material is a useful marker to predict the potential of compounds to induce nausea and/or emesis in non-vomiting rodents.
\end{abstract}

Key words: 5-HT (5-Hydroxytryptamine, serotonin) ${ }_{3}$ receptor, Chemotherapeutics, Gastric retention, Rats, Nausea, Emesis

\section{INTRODUCTION}

Unidentified complaints in the digestive system are often observed as side effects with many medicines, especially in cancer chemotherapeutics. The chemotherapeutics-induced nausea and emesis lead to poor treatment compliance and these can worsen patients' quality of life. Cancer chemotherapeutics should be chosen to have minimal adverse effects and anti-emetic drugs for them should also develop in a hurry.

Dogs (Andrews et al., 2001), ferrets (Lau et al., 2005; Nakayama et al., 2005), house musk shrews (Suncus murinus, Yamamoto et al., 2004; Nakayama et al., 2005), and pigeons (Tanihata et al., 2004) have been used in studies of nausea and emesis, but all have disadvantages of one type or another. Dogs are gold standard animal in the research area while requiring large amounts of chemical, while ferrets, Suncus murinus and pigeons are not commonly used for pharmacological and toxicological assessment. Rats and mice, as standard laboratory animals, present difficulties because of their inability to vomit, but if appropriate models were available, they would be the optimal species.

We empirically know that pelleted food or other substances were accumulated in the stomach after administration of emetic agents in rodents. Then, we have reported that cancer chemotherapeutics-induced delay in gastric empty in mice is mediated via $5-\mathrm{HT}_{3}$ receptors and sol-

Correspondence: Kentaro Ando (E-mail: akentaro@mail.ecc.u-tokyo.ac.jp) 
id materials is better than liquid meal for prediction of the chemotherapeutics-induced emesis and/or nausea (Ando and Takagi, 2011). Several other attempts to estimate drug-induced nausea and emesis in rats have been reported previously (Mitchell et al., 1976; Yamamoto et al., 2005, 2007; Malik et al., 2007). These reports suggests that pica behavior and salivary amylase secretion could be used to predict emesis in rats. Although the methods mentioned above need some care, our method is very simple. In the present study, we examined the prediction of cancer chemotherapeutics-induced emetogenic effects and the role of $5-\mathrm{HT}_{3}$ receptor in them by the solid gastric retention using resin beads in rats.

\section{MATERIALS AND METHODS}

\section{Animals}

All experiments were performed according to the Guidance for care and use of laboratory animals at the test site and the Japanese Pharmacological Society. Male Sprague-Dawley rats (7 week-old) were purchased from Japan SLC (Shizuoka, Japan) and they were housed every 5 rats per cage on wire-mesh in a room with a 12-hr light/12-hr dark cycle (lights on between 7:00 and 19:00) at a constant temperature $\left(22 \pm 3^{\circ} \mathrm{C}\right)$ and humidity $(55 \pm$ 20\%). Pelleted food (MF, Oriental Yeast, Osaka, Japan) and water were available ad libitum. After quarantine and acclimation for at least 3 days, rats in good condition were used. Rats were fasted overnight in wire-mesh cages individually to prevent coprophagy before experiments.

\section{Drugs and chemicals}

The following drugs and chemicals were purchased: cisplatin (Maruko, Aichi, Japan), doxorubicin (Mercian, Tokyo, Japan), ondansetron (Zofran ${ }^{\circledR}$ injection, GlaxoSmithKline, Tokyo, Japan) and copper sulfate (Kanto Chemical., Osaka, Japan).

\section{Solid gastric retention by resin beads (Beads method)}

Resin beads (diameter: $0.8 \mathrm{~mm}$, DIAION SA10A, Mitsubishi Chemical, Tokyo, Japan) were colored blue with methylene blue solution before use for looking out them easily from gastric contents. Each rat was orally given distilled water $(0.5 \mathrm{ml} / \mathrm{rat})$ containing 40 resin beads via a plastic feeding tube. The resin beads used these studies were more suitable than beads made with metals or glasses in size, hardness, weight and stainability. The stomach was removed at $1 \mathrm{hr}$ after gavage of beads and cut along the greater curvature under carbon dioxide anesthesia. The contents were washed out into a petri dish and the number of beads in it was carefully counted. The gastric retention rate was calculated with the following formula; gastric retention $(\%)=$ (the number of beads in the stomach) $/ 40 \times 100$. Beads were given immediately after administration of the drugs except with cisplatin, when there was a $1 \mathrm{hr}$ delay. Ondansetron $(3-100 \mu \mathrm{g} / \mathrm{kg})$, cisplatin $(0.1-3 \mathrm{mg} / \mathrm{kg})$ and doxorubicin $(0.3-10 \mathrm{mg} / \mathrm{kg})$ were intravenously given and copper sulfate $\left(\mathrm{CuSO}_{4}\right.$, $1-30 \mathrm{mg} / \mathrm{kg}$ ) was orally given to rats, respectively.

Interactions of ondansetron with sub-maximal dose of cisplatin, doxorubicin and copper sulfate on the solid gastric retention were also investigated. Ondansetron was injected from tail vein 15 min before the administration of the beads.

\section{Statistical analysis}

Data presented as mean \pm standard deviation (S.D.) values from 6 to 8 rats were compared between the controls and the drug groups by one-way analysis of variance followed by Dunnett multiple comparison tests. In the interaction study with ondansetron, statistical analysis between the controls and the drug groups were conducted by one-way analysis of variance followed by Dunnett multiple comparison tests, if a comparison between vehicle (non-treatment) and control (test drug only) performed by Student's $t$-test was statistically significant. If the comparison between vehicle and control was not statistically significant, further comparison between controls and the drug groups was not performed. A value of $\mathrm{P}<0.05$ (double-sided) was considered statistically significant.

\section{RESULTS}

Ondansetron itself tended to decrease the gastric retention up to $100 \mu \mathrm{g} / \mathrm{kg}$, but not statistically significant (Fig. 1).

Copper sulfate tended to reduce the gastric retention up to $3 \mathrm{mg} / \mathrm{kg}$, but enhanced the gastric retention from $10 \mathrm{mg} / \mathrm{kg}$ (Fig. 2). Ondansetron significantly and dosedependently antagonized the copper sulfate-induced gastric enhancement at $100 \mu \mathrm{g} / \mathrm{kg}$ (Fig. 2).

Cisplatin significantly enhanced the gastric retention from $0.3 \mathrm{mg} / \mathrm{kg}$ and ondansetron significantly and dosedependently antagonized the cisplatin-induced enhancement from $30 \mu \mathrm{g} / \mathrm{kg}$, respectively (Fig. 3)

Doxorubicin significantly enhanced the gastric retention from $3 \mathrm{mg} / \mathrm{kg}$ and ondansetron significantly and dose-dependently antagonized the doxorubicin-induced enhancement from $10 \mu \mathrm{g} / \mathrm{kg}$, respectively (Fig. 4). 
Enhanced gastric retention as a marker for emetic potential of agents in rats

\section{DISCUSSION}

Emptying of solids from the stomach has been reported to be much later than that of liquid in dogs (Hinder and Kelly, 1977). Although the stomach of rats and mice is anatomically different from that in dogs, the emptying rates for solid and liquid meals appear to be comparable at least in mice (Ando and Takagi, 2011) comparing to dogs. Our previous results apparently suggested that the beads method was more sensitive to detect enhancement of the gastric retention than the liquid meals method.

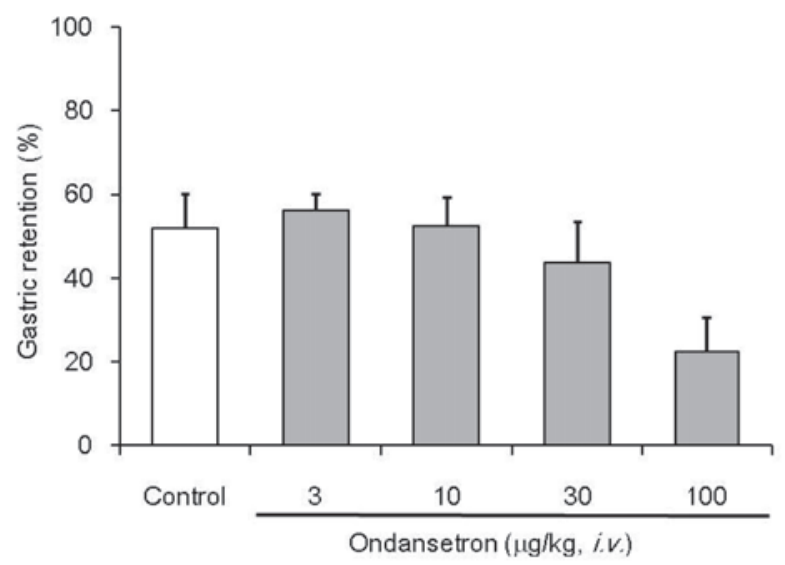

Fig. 1. Effects of ondansetron $(3-100 \mu \mathrm{g} / \mathrm{kg}$ ) alone on the gastric retention in rats. Ondansetron was intravenously given to rats. Each data represents mean \pm S.D. values from 7 or 8 rats per group. No statistical differences are observed in each group.

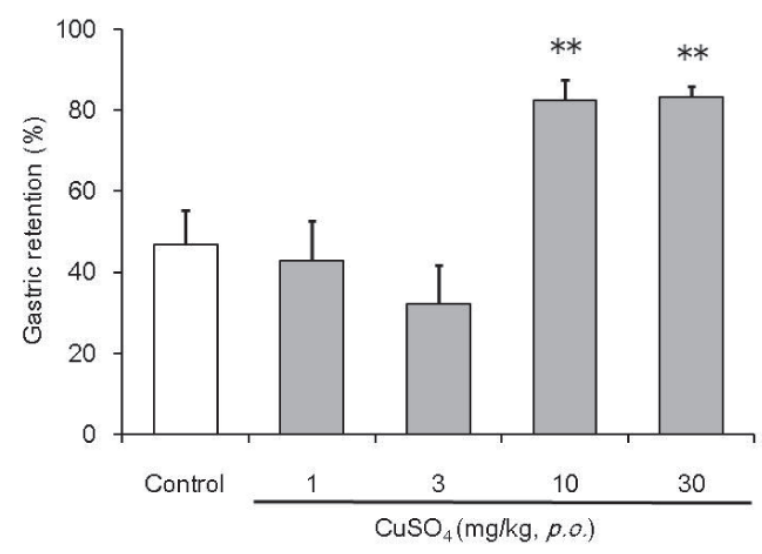

The present study provided clear evidence that cancer chemotherapeutics-induced enhancement of the solid gastric retention in rats is mediated via the $5-\mathrm{HT}_{3}$ receptor as well as in mice (Ando and Takagi, 2011). Copper sulfate, which evokes vomiting via stimulation of the terminals of the visceral afferents innervating the stomach wall in humans, dogs, cats, and ferrets (King, 1990), is a standard emetic chemical. Visceral afferents innervating the stomach wall have also been observed in mice (Green and Dockray, 1988) and rats (Green and Dockray, 1988; Takeda et al., 1993) suggesting that the copper sulfateinduced enhancement of the solid gastric retention probably occurred by the same physiological mechanisms as observed in non-rodents. Emesis induced by copper sulfate in dogs, Suncus murinus and ferrets has been observed at $3 \mathrm{mg} / \mathrm{kg}$ (Nakamura et al., 1995), $120 \mathrm{mg} / \mathrm{kg}$ (Yamamoto et al., 2004) and $25 \mathrm{mg} / \mathrm{kg}$ or less (Costall et al., 1990), respectively, while enhancement of the solid gastric retention was observed in rats at $10 \mathrm{mg} / \mathrm{kg}$ or more in our present studies. Oral administration of copper sulfate induces kaolin consumption, analogous to emesis in rats, from $4 \mathrm{mg} / \mathrm{kg}$ or more (Takeda et al., 1993). These results suggest that copper sulfate-induced emesis is predictable with the comparable sensitivity to previous reports in rats, which do not vomit, if the enhancement of the solid gastric retention by the beads method is used as the index. Although $5-\mathrm{HT}_{3}$ receptor has reported not to play an important role in copper sulfate-induced emesis in ferret (Nakayama et al., 2005), there was no report about mechanisms in copper sulfate-induced emesis in rodents. It also becomes clear that copper sulfate-induced

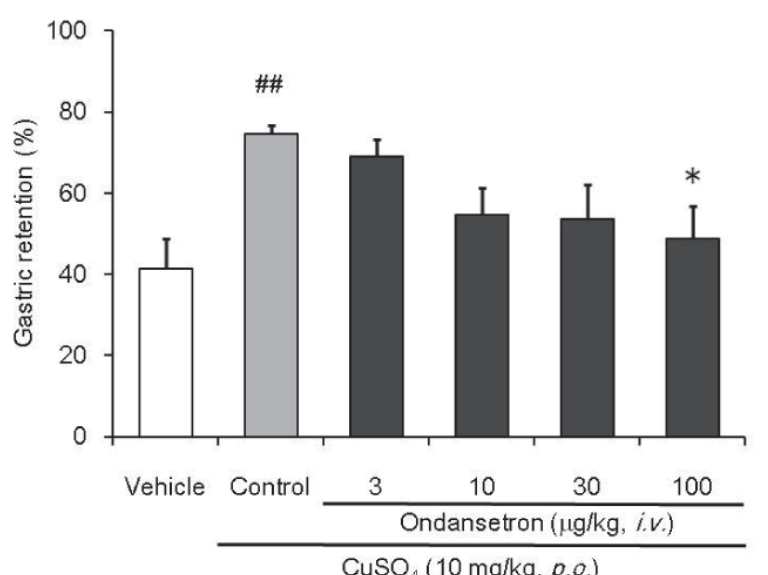

Fig. 2. Effects of copper sulfate $\left(\mathrm{CuSO}_{4}, 1-30 \mathrm{mg} / \mathrm{kg}\right)$ alone and coadministration with ondansetron on the gastric retention in rats. Copper sulfate and ondansetron were orally and intravenously given to rats, respectively. Each data represents mean \pm S.D. values from 7 or 8 rats per group. Statistical differences from control and vehicle are indicated as ${ }^{*} \mathrm{P}<0.05,{ }^{* *} \mathrm{P}<0.01$ and $\# \mathrm{P}<0.01$, respectively. 

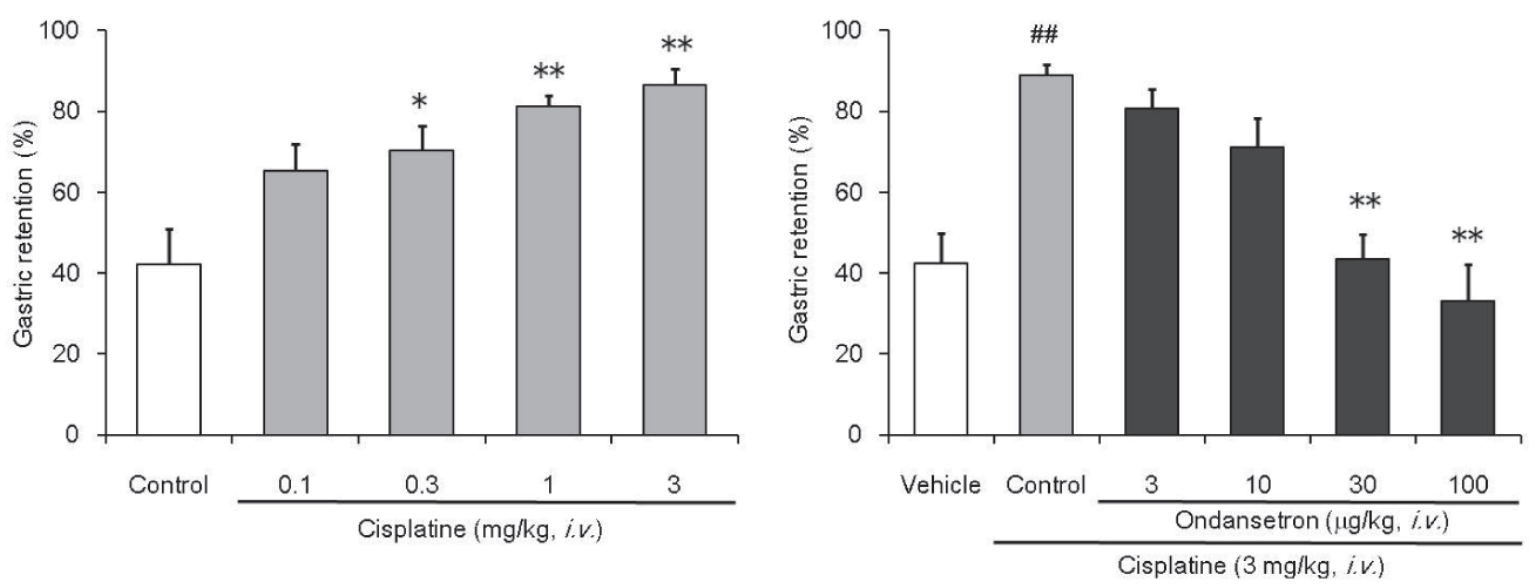

Fig. 3. Effects of cisplatin (0.1-3 mg/kg) alone and coadministration with ondansetron on the gastric retention in rats. Cisplatin and ondansetron were intravenously given to rats. Each data represents mean \pm S.D. values from 6 to 8 rats per group. Statistical differences from control and vehicle are indicated as ${ }^{*} \mathrm{P}<0.05,{ }^{* *} \mathrm{P}<0.01$ and ${ }^{\#} \mathrm{P}<0.01$, respectively.
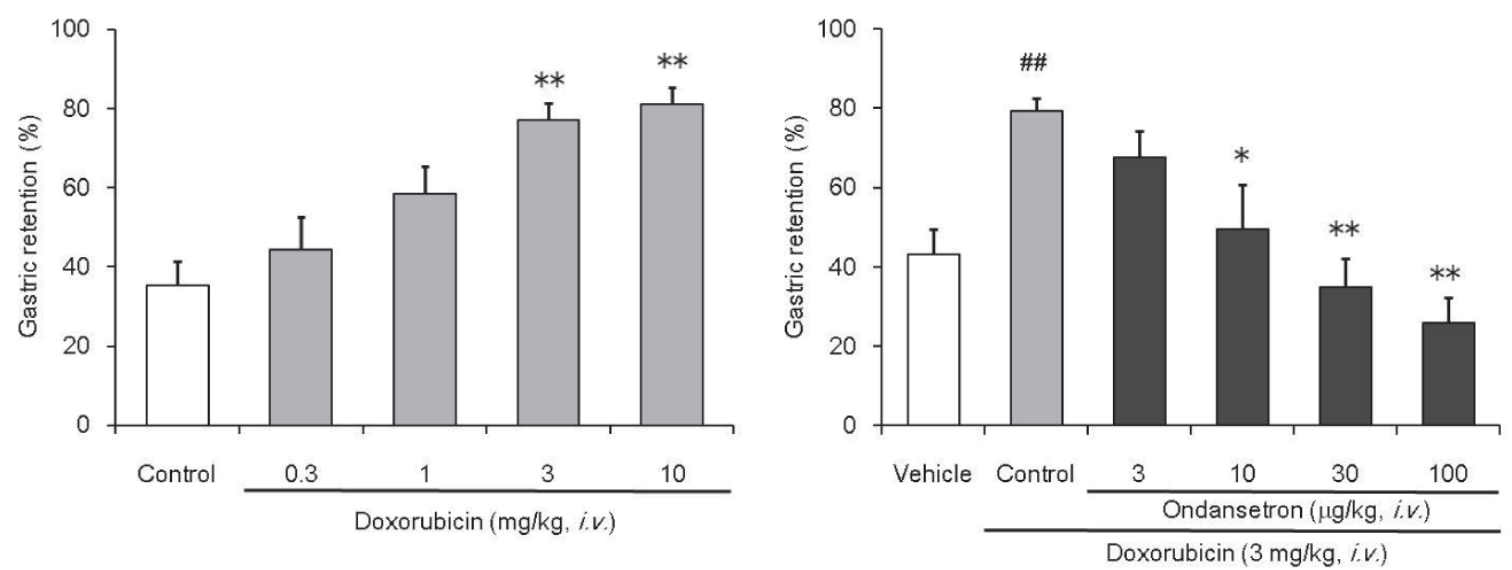

Fig. 4. Effects of doxorubicin $(0.3-10 \mathrm{mg} / \mathrm{kg})$ alone and coadministration with ondansetron on the gastric retention in rats. Doxorubicin and ondansetron were intravenously given to rats. Each data represents mean \pm S.D. values from 7 or 8 rats per group. Statistical differences from control and vehicle are indicated as ${ }^{*} \mathrm{P}<0.05,{ }^{* *} \mathrm{P}<0.01$ and ${ }^{\#} \mathrm{P}<0.01$, respectively.

enhancement of the solid gastric retention is mediated via the $5-\mathrm{HT}_{3}$ receptor in rats, although it was unclear in mice (Ando and Takagi, 2011).

Cisplatin and doxorubicin cause release of serotonin from enterochromaffin cells in the upper gastrointestinal tract and this then stimulates gastrointestinal visceral afferents via $5-\mathrm{HT}_{3}$ receptors, resulting in vomiting (Andrews et al., 1988). Intravenous doses of cisplatin, with which emesis is consistently observed in experiments, are $3.0 \mathrm{mg} / \mathrm{kg}$ for $\mathrm{dog}, 7.8 \mathrm{mg} / \mathrm{kg}$ for ferret and $1.25 \mathrm{mg} / \mathrm{kg}$ for human (King, 1990), respectively. The degree apparently increased from $10 \mathrm{mg} / \mathrm{kg}$ of intravenous administration in ferrets (Costall et al., 1990).
Intravenous doses of doxorubicin induced emesis over $2.0 \mathrm{mg} / \mathrm{kg}$ for dog (Haga et al., 2000) and $40 \mathrm{mg} / \mathrm{kg}$ for Suncus murinus (Matsuki et al., 1988), respectively. The enhancement of these cancer chemotherapeutics-induced solid gastric retention by the beads method suggest that rats as well as mice can be used in prediction of druginduced vomit at comparable or lower doses compared to non-rodents.

Although ondansetron itself tended to enhance the gastric emptying in rats, it apparently and dose-dependently antagonized the cisplatin- and the doxorubicin-induced enhancement of the gastric retention. This suggests that the enhancement of the gastric retention in rats is medi- 
Enhanced gastric retention as a marker for emetic potential of agents in rats

ated via $5-\mathrm{HT}_{3}$ receptor and can be used to predict cancer chemotherapeutics-induced emesis and/or nausea as well as in mice.

In conclusion, the enhancement of solid gastric retention produced by cisplatin and doxorubicin in rats appears to be mediated by $5-\mathrm{HT}_{3}$ receptor as well as in mice, although detail mechanisms such as implication of dopamine 2 receptor and tachykinin neurokinin 1 receptor, and delayed emetic responses by cancer chemotherapeutics in rats remain unclear. Therefore, the beads method in rats can be recommended as a simple and suitable approach to predict drug-induced emesis and/or nausea, especially with cancer chemotherapeutics as well as in mice.

\section{REFERENCES}

Ando, K. and Takagi, K. (2011): Solid gastric emptying mediated by the serotonin $(5-\mathrm{HT})_{3}$ receptor in mice is a simple marker to predict emesis. J. Toxicol. Sci., 36, 23-29.

Andrews, P.L.R., Kovacs, M. and Watson, J.W. (2001) : The antiemetic action of the neurokinin ${ }_{1}$ receptor antagonist CP-99,994 does not require the presence of the area postrema in the dog. Neurosci. Lett., 314, 102-104.

Andrews, P.L.R., Rapeport, W.G. and Sanger, G.J. (1988) : Neuropharmacology of emesis induced by anti-cancer therapy. Trends. Pharmacol. Sci., 9, 334-341.

Costall, B., Domeney, A.M., Naylor, R.J., Owera-Atepo, J.B., Rudd, J.A. and Tattersall, F.D. (1990) : Fluphenazine, ICS 205-930 and dl-fenfluramine differentially antagonise drug-induced emesis in the ferret. Neuropharmacology, 29, 453-462.

Fukui, H., Miwa, E., Iwachido, T., Kitaura, H. and Furukawa, H. (2010) Various emetogens increase the secretion of salivary amylase in rats: a potential model in emesis research. J. Pharmacol. Sci., 113, 143-52.

Green, T. and Dockray, G.J. (1988) : Characterization of the peptidergic afferent innervation of the stomach in the rat, mouse and guinea-pig. Neuroscience., 25, 181-193.

Haga, K., Inaba, K., Syoji, H. and Hashimoto, T. (2000) : Delayed emesis induced by the chemotherapeutic agent doxorubicin hydrochloride in dogs (in Japanease). Nihon Yakurigaku Zasshi., 116, 313-320.

Hinder R.A. and Kelly K.A. (1977): Canine gastric emptying of solids and liquids. Am. J. Physiol., 233, E335-340.

King, G.L. (1990) : Animal models in the study of vomiting. Can. J. Physiol. Pharmacol., 68, 260-268.

Lau, A.H., Kan, K.K., Lai, H.W., Ngan, M.P., Rudd, J.A., Wai, M.K. and Yew D.K.W. (2005) : Action of ondansetron and CP-99,994 to modify behavior and antagonize cisplatin-induced emesis in the ferret. Eur. J. Pharmacol., 506, 241-247.

Malik, N.M., Liu, Y.L., Cole, N., Sanger, G.J. and Andrews, P.L.R. (2007) : Differential effects of dexamethasone, ondansetron and a tachykinin NK1 receptor antagonist (GR205171) on cisplatininduced changes in behaviour, food intake, pica and gastric function in rats. Eur. J. Pharmacol., 555, 164-173.

Matsuki, N., Ueno, S., Kaji, T., Ishihara, A., Wang, C.H. and Saito, H. (1988) Emesis induced by cancer chemotherapeutic agents in the Suncus murinus: a new experimental model. Jpn. J.
Pharmacol., 48, 303-306.

Mitchell, D., Wells, C., Hoch, N., Lind, K., Woods, S.C. and Mitchell, L.K. (1976) : Poison induced pica in rats. Physiol. Behav., 17, 691-697.

Nakamura, H., Asano, T., Haruta. K. and Takeda. K. (1995) : Gastrointestinal motor inhibition by exogenous human, salmon, and eel calcitonin in conscious dogs. Can. J. Physiol. Pharmacol., 73, 43-49.

Nakayama, H., Yamakuni, H., Higaki, M., Ishikawa, H., Imaizumi, K., Matsuo, M. and Mutoh, S. (2005) : Antiemetic activity of FK1052, a 5-HT3- and 5-HT4-receptor antagonist, in Suncus murinus and ferrets. J. Pharmacol. Sci., 98, 396-403.

Takeda, N., Hasegawa, S., Morita, M., and Matsunaga, T. (1993) : Pica in rats is analogous to emesis: An animal model in emesis research. Pharmacol. Biochem. Behav., 45, 817-821.

Tanihata, S., Oda, S., Nakai, S., and Uchiyama, T. (2004) : Antiemetic effect of dexamethasone on cisplatin-induced early and delayed emesis in the pigeon. Eur. J. Pharmacol., 484, 311321.

Yamamoto, K., Nakai, M., Nohara, K. and Yamatodani, A. (2007) : The anti-cancer drug-induced pica in rats is related to their clinical emetogenic potential. Eur. J. Pharmacol., 554, 34-39.

Yamamoto, K., Ngan, M.P., Takeda, N., Yamatodani, A. and Rudd, J.A. (2004) : Differential activity of drugs to induce emesis and pica behavior in Suncus murinus (house musk shrew) and rats. Physiol. Behav., 83, 151-156.

Yamamoto, K., Nohara, K., Furuta, T. and Yamatodani, A. (2005) : Ondansetron, dexamethasone and an NK1 antagonist block radiation sickness in mice. Pharmacol. Biochem. Behav., 82, 24-29. 